The effect of spoilage and handling on the bacterial flora of fish was discussed by Dr. J. M. Shewan (Torry Research Station, Aberdeen). Although the flesh of newly caught fish is sterile, bacteria are always present on the skin and gills and in the gut. The flora consist of approximately 50 per cent Pseudomonas, 40 per cent Achromobacter spp., 5 per cent Flavobacterium, 2 per cent Corynebacterium and 2 per cent Micrococcus with 1 per cent miscellaneous groups. Despite repeated attempts, no enterobacteria have been found. The latter would be expected from polluted waters. This division of flora holds for haddock, cod, lemon sole and skate, the four North Sea species studied. It appears to hold also for herring from surrounding sea areas, but differs markedly from the findings for cod from Canada and for several species from Australia. The differences are attributed to environment. The bulk of fish landed in Britain comes from distant waters and has been five to eighteen days in ice. During storage the flora changes. By the third to fourth day in ice the lag phase of bacterial growth has passed and by the tenth to twelfth day, the end of the log phase has been reached with counts in the region of $10^{7}$ to $10^{9}$ per cm. ${ }^{2}$ of skin or per gram of gill tissue. During this time pseudomonads increase steadily until they constitute 90 per cent of the flora and Achromobacter spp. about 5 per cent.

After handling on shore the relative proportions in the bacterial load can alter considerably. This has been found in recent work on the commercial filleting process, in which shigellas and salmonellas have never been encountered during tests. Small numbers of true frcal coli have been found at the filleting stage, and coagulase-positive staphylococei found in 30 per cent of fillets examined. However, the results are in accord with existing information on the incidence of food-poisoning caused by fish and show that fresh fish is one of the safest articles of diet in Britain.

J. Davidson

\section{CONTROL OF THE PLANT ENVIRONMENT}

$\mathrm{T}$

HE University of Nottingham held its fourth Easter school in agricultural science during April 15-17, on "Control of Environment in Crop Experimentation". Since the past century, physiologists have been studying various aspects of plant growth under conditions in which one or more factors of the environment were controlled, but the possibilities of that approach were restricted by the difficulty of growing healthy plants for any length of time in artificial light. Within the past thirty years the introduction of many new types of electric lamp, with characteristics more suitable for plant growth, has made it possible to grow normal plants in opaque rooms even to maturity, under conditions where several environmental factors can be controlled simultaneously.

A number of workers became interested in this approach, but the development of Dr. F. W. Went's 'phytotron' at the Earhart Plant Research Laboratory, Pasadena, California, suggested new possibilities of providing a wide range of different controlled environments within a single installation. Interest grew in the use of environmental control for experimental work, and although there is nothing in Britain as elaborate as the Californian installation, a recent survey showed that some seventy university depart- ments and research stations in Britain now have facilities for work in controlled environments (Univ. Nottingham Dep. Hort. Misc. Pub. 8).

This approach offers attractive possibilities in several fields of research, ranging from fundamental aspects of plant physiology and genetics to applications of immediate importance in plant breeding and agronomy. The wide interest in the field was shown by the attendance of two hundred scientists at the Easter school, including physicists, chemists, biologists, agronomists, horticulturists and engineers, all with a common interest in environmental control but looking at its problems from different points of view. A vigorous exchange of views between such various disciplines proved to be both stimulating and profitable.

Three main themes dominated the proceedings, namely, the relation between the plant and its environment, methods of controlling the environment in experimental work, and the possible applications of environmental control in crop husbandry.

Prof. S. J. Wellensiek (Agricultural University, Wageningen) opened the school by discussing the plant and its environment in general terms, distinguishing between variations caused by genetical factors, soil conditions and the aerial environment. After discussing the effects of the main individual factors, with special reference to shifts in temperature optima according to the phase of growth, attention was directed to important interactions between several of the factors, notably photosynthetic light and temperature, photoperiod and temperature, and soil-moisture and relative humidity of the air. Experiments on peanut plants under controlled conditions have revealed relations between weather factors which were hitherto unsuspected. For example, growth of stems and increase in number of flowers are closely linked with soil-moisture, optimal development being associated with conditions where the soil remains relatively moist. When soil is allowed to develop even moderately high moisture tensions between irrigations, rate of flowering falls off, but there is a rapid increase in the number of flowers two days after each application of water. Interactions have also been demonstrated between soil-moisture conditions and the relative humidity of the air, a high relative humidity giving best growth, especially during the first month.

Attention then turned to detailed methods of using controlled environments in the study of plant behaviour. Dr. W. W. Schwabe (Research Institute of Plant Physiology, London) discussed the differential effects of some environmental factors on plant development, instancing rates of differentiation of primordia and of leaf expansion as examples of the morphogenetic changes which are affected by factors such as temperature, day-length and intensity of illumination. Prof. E. C. Wassink (Agricultural University, Wageningen) placed the emphasis on plant growth, giving examples of the effects of various environmental factors on such diverse aspects of growth as the production of flowers in bulbous irises and the hearting of lettuce plants. A two-stage growth cabinet has been used for subjecting roots and shoots of a plant to different temperatures to study this interaction, which has wide implications in agronomy, since disharmony between soil and air temperatures is frequently the cause of depressed growth in crop plants. Prof. P. T. Thomas (University College, Aberystwyth) showed how controlled eil. vironments could be used in plant genetics for the 
study of the complicated interactions between genotype and environment. A stage appears to have been reached where closer collaboration between the geneticist and the physiologist might be to their mutual benefit.

Light, wind and water were then singled out for separate consideration as important factors, both of experimental and natural environments. Prof. R. H. Stoughton and Dr. Daphne Vince (University of Reading) discussed the physical attributes of light in relation to biological responses, taking the growth of a plant as an integrated function of the photosynthetic and formative effects of the various spectral components of light. These effects are being studied under lights of different spectral composition, and data were given on leaf expansion, intermode extension and net assimilation under various light sources. Wind as a factor in plant growth was the subject of a paper by Dr. F. H. Whitehead (University of Oxford), who gave an account of an investigation on the effects of wind on the growth of alpine plants under various exposure conditions on a mountain top in Italy, and then described experiments under controlled air-speeds in a wind tunnel. Conclusions were drawn regarding the relation between results in the field and in the laboratory. The complexities of the plant/soil/water system were described by Dr. J. P. Hudson (University of Nottingham), who showed the limitations of using constantly moist soil conditions in experimental work, and the advantages of providing plants with controlled but fluctuating moisture conditions. Ihis requires a rigorous control of experimental conditions, but leads to the concept of detinable and reproducible water-regimes, which appear to offer a sensitive technique for the study of plant responses to soil water. It became clear in all these papers that the meteorologist, ecologist, physiologist and agronomist could also, with advantage, meet more often to exchange ideas based on their different approaches to the same phenomena.

'lechnical aspects of environmental control were the theme of two speakers. Mr. W. J. C. Lawrence (John Innes Horticultural Institution, Bayfordbury), discussing the glasshouse as an environment for plant experiments, appraised the possibilities of achieving a high degree of control of various factors, especially temperature, light and relative humidity. Several interesting suggestions were made for improving the efficiency of glasshouses used for experimental work, including the possibility of end-to-end ventilation instead of the traditional lateral method. The central problem is how to reduce gradients of environmental factors in both space and time. Mr. L. G. Morris (National Institute of Agricultural Engineering, Wrest Park) described problems involved in the design of growth rooms and cabinets used for plant experiments and appealed for more information on the tolerances which could be accepted in time and space. Many installations, designed without adequate data on their use or characteristics, are either much too elaborate for the uses to which they are put, or else will not provide the degree of control that is needed. Both faults, basic in the design of the equipment, lead to waste and frustration.

In the final paper, concerning agronomical aspects of environmental control, Prof. A. H. Bunting (University of Reading) was invited both "to trail his coat' and peer into the future. This he most obligingly did, in a stimulating paper that concluded the proceedings on a high note of interest in the possibilities of increasing crop yields, even in the open, by slight but carefully controlled changes in various factors of the physical environment. 'The fields offering the best prospects of striking improvements in crop yields appear to be the more efficient use of irrigation water, the application of nutrients by leaf sprays at critical stages in plant development, and the use of lowintensity irradiation to break the period of darkness and induce earlier flowering in some species. This should be coupled with intensive breeding programmes to develop varieties that can take maximum advantage of more carefully controlled environments.

In addition to the main sessions, two evening meetings were devoted to technical descriptions of installations now being used for the control of environment. Dr. A. M. M. Berrie (University of Glasgow) described the design and construction of the Earhart Laboratory, illustrating his account with a film lent by Dr. Went and his own transparencies. He also described Prof. R. Bouillènne's installation at the University of Liège. In a prolonged discussion on the best policy to adopt in planning controlled experimental environments, the national advantages of having a small number of large, comprehensive and necessarily expensive 'phytotrons' were compared with having a much larger number of simpler and cheaper instellations. The general opinion seemed to be that, at the present stage of knowledge, the advantage lay in the latter approach, which was likely to produce more results, more quickly, for a given total expenditure on capital and running costs. Several patterns of growth rooms were also described, together with relatively small and inexpensive growth cabinets, of elegant design, that are giving a high degree of precision of control of light, tem. perature and humidity.

1here were also about thirty demonstrations of equipment for the control of environment, instruments for measuring environmental factors and the effects of environment on plant growth. One of the limitations in work on environmental effects is that none of the light-sources at present available will give intensities approaching those which occur on bright summer days in Britain. Great interest was shown in several lamps of new design that should enable higher light intensities to be provided although, of course, their use will also increase the difficulties of keeping temperatures down to reasonable levels. There was also general interest in labour-saving equipment, such as automatically controlled devices for blacking-out plants, reflecting the difficulties which workers often experience in operating controls at awkward hours and at the week-end. 'The study of environmental effects is apt to become an operation extending over twenty-four hours per day, for seven days a week, and methods of automatic control are exercising many ingenious minds.

Various practical applications of environmental control were demonstrated. A series of raspberry plants in all phases of growth showed how the lifecycle could be shortened or lengthened at will, to provide plants in any phase of growth, at any time of year, irrespective of seasonal weather. This enables research on a particular aspect to proceed all the year round and illustrates a use of controlled environments which is still only in its infancy. Various demonstrations showed the effects of environmental factors on the growth of potato, cucumber, lettuce, rhubarb and other plants, while a method was suggested of using emergence of seedlings as an indicator of environmental conditions in the soil. 
Although this hard-working school only lasted for forty eight hours, the growing interest in environmental control was amply demonstrated. It was generally felt that we have only just begun to realize the potentialities of this relatively new approach, which offers a wealth of possibilities in the study of plants and cultivation of crops. The proceedings will be published in full elsewhere.

\section{J. P. Hunson}

\section{NATIONAL RESEARCH DEVELOP. MENT CORPORATION}

\section{REPORT FOR 1955-56}

$\mathrm{T}$ HE report of the National Research Development Corporation* for the year ended June 30, 1956, is again limited to a factual review. Government departments and research councils assigned patent rights in 153 cases compared with 135 in 1954-55, twenty-three of the total of 200 coming from universities, three from industrial research associations and eight from charitable organizations. Of the 438 inventions communicated to the Corporation during 1955-56 (compared with 597 during 1954-55), 171 were from Government departments and research councils, twenty from official organizations of the British Commonwealth, eight from industrial research associations, forty-nine from universities and 188 from private firms and individuals, 171 being British. Holdings of British and foreign patents and patent applications at June 30, 1956, included 469 United Kingdom applications and 604 granted patents, 1,039 overseas patent applications and 773 granted patents. The accounts show revenue from exploitation of inventions amounting to $£ 75,912$, compared with $£ 40,617$ in $1954-55$ and and $£ 28,857$ in $1953-54$.

Of projects initiated in previous years, the report notes that the six big electronic digital computers are now complete and five have been installed, while the production prototype Pegasus computer has proved entirely satisfactory : eight of the nine ordered have been bespoken, and the Corporation proposes to reserve the ninth for its own use. Work was initiated on a project to pass direct to a transistorized all-core type of computer with massive tape storage and handling equipment, and also on a project on the use of an Elliott Brothers type 405 data-processing system for the inventory of engineering stores and the production control of complex equipment. This year's harvest period is to be devoted to a study of the current performance of the Packman potato harvester as a guide to future policy. A much fuller evaluation of the performance of the bumers under various conditions of preheat is contemplated in the acetylene synthesis project at the Imperial College of Science and Technology. Satisfactory progress is being made in the redesign of the stereoscopic motion picture camera to adapt it for high aspect (widescreen) pictures, and the printed electrical circuits projects is now receiving industrial support.

Among the new projects, the Corporation is supporting the development, in the Department of Electrical Engineering at the University of Manchester, of a variable-speed squirrel-cage type

* National Research Development Corporation. Report and Statement of Accounts for the year 1st July, 1955, to 30th June, 1956. Pp. ii 16. (London: H.M. Stationery Office, 1957.) 18. net. induction motor, and the National Institute for Research in Dairying, with financial support from the Corporation, has developed a method for preparing a frozen milk which can be stored for at least twelve months without deterioration. Some financial support was also given to the National Institute of Agricultural Engineering for the development of a small potato harvester to fill the gap between the large combine machines and potato spinners and elevator diggers. The report gives a further list of licensed inventions being exploited by industry on a scale which supplies the Corporation with appreciable revenue. These now include the production of hecogenin from sisal, the weedkillers derived from phenoxybutyric acid, the Royal Aircraft Establishment fire and heat detector for aircraft, and the insecticidal bomb invented at the Chemical Defence Experimental Establishment of the Ministry of Supply.

\section{BREEDING BEHAVIOUR OF CICHLIDS}

ITHOUGH the breeding behaviour of cichlid fishes in aquaria has been studied by several authors, very little is known about their behaviour in natural waters. A paper by A. H. Lowe presents results from field studies on the breeding behaviour of $T$. karomo Poll and T. variabilis Boulenger (Behaviour, 9, No. 2-3 ; Leyden, 1956).

Tilapia species can be divided into three groups according to differences in their breeding behaviour : 'guarders', 'male mouth-brooders' and 'female mouthbrooders'. Both the species considered by Lowe are 'female mouth-brooders'.

Breeding males of $T$. karomo congregate on the spawning grounds and each male establishes a territory wherein he prepares a nest. The males have a brightly coloured breeding dress, including a long genital tassel; they are slightly larger than the females, which are less brightly coloured. The nests are plaques of clean sand, often raised on mounds; nest cleaning is carried out by the male by 'mouthing', 'nosing' and 'fanning'. Lowe also describes the other activities of the male before and between spawnings. Females cruise over the spawning grounds singly or in small shoals; the male swims out to meet them as they enter his territory, turns and leads back to the nest. Often there is very little pre-spawning display and spawning may be complete in two to five minutes. After laying, the female collects the eggs in her mouth and leaves the spawning ground; the male remains in his territory and immediately starts courting other females. T. karomo females stay among the water-plants when brooding. They probably have three or four broods in succession; it is not known for how long the young are brooded.

The breeding behaviour of T. variabilis in Lake Salisbury (Uganda) was investigated and was found to be very similar to that of $T$. karomo.

Discussing the similarities and differences in behaviour between $T$. karomo and $T$. variabilis, Lowe describes how $T$. variabilis has a distinct piebaldand-orange colour form; nearly all these piebald fish are females. 'Normal' males must, it seems, breed with these.

The areas which are suitable for spawning may be determined by the nature of the bottom and by the availability of dissolved oxygen. Young T. karomo 